\title{
Uwarunkowania oraz konsekwencje wymuszonej fluktuacji sprzedawców
}

\begin{abstract}
Krzysztof Cybulski*
Wptyw zarówno dobrowolnej, jak $i$ wymuszonej fluktuacji sprzedawców na praktycznie wszystkie organizacje dziatające $w$ różnych branżach jest kosztowny i niezmiernie uciażliwy. $W$ niniejszym tekście autor uzasadnia tezę, że coraz bardziej dotkliwe zjawisko, fluktuacji sprzedawców również wymuszonej jest przede wszystkim konsekwencja ztego zarządzania organizacjami sprzedażowymi. Odzwierciedla ono brak doświadczenia oraz deficyt podstawowych kompetencji oraz umiejętności menedżerów sprzedaży do radzenia sobie z problemami podleglych zespotów sprzedażowych.

Precyzyjna analiza zjawiska wymuszonej fluktuacji nie tylko pozwolita na identyfikacje jej przyczyn i konsekwencji, ale ponadto umożliwiła wskazać konkretne działania konieczne dla ograniczenia jej skali.
\end{abstract}

Słowa kluczowe: wymuszona fluktuacja sprzedawców, koszty fluktuacji, przyczyny wymuszonej fluktuacji, konsekwencje fluktuacji, redukowania poziomu fluktuacji.

Nadesłany: 28.11.2016 | Zaakceptowany do druku: 28.12.2016

\section{Determinants and Consequences of Involuntary Turnover of Sales Personnel}

Both voluntary and involuntary turnover of sales personnel has a costly and troublesome impact on virtually all firms operating in different industries. In this paper the author argues that an increasingly important phenomenon of especially involuntary sales force turnover derives mostly from poor managerial practices and, to a certain extent, reflects the inability of sales managers to deal with sales teams problems.

An accurate analysis of the phenomenon allowed for identifying practical solutions and showing specific necessary actions that would reduce the volume of sales force involuntary turnover and curb its negative consequences.

Keywords: involuntary turnover of salespeople, turnover costs, causes of involuntary turnover, turnover consequences, reduction of salespeople turnover level.

Submitted: 28.11.2016 | Accepted: 28.12.2016

JEL: A12

\footnotetext{
Krzysztof Cybulski - dr hab., Wydział Zarządzania, Uniwersytet Warszawski.

Adres do korespondencji: Wydział Zarządzania, Uniwersytet Warszawski, ul. Szturmowa 1/3, 02-678 Warszawa; e-mail: kcybulski@wz.uw.edu.pl.
} 


\section{Wprowadzenie}

Fluktuacja sprzedawców od dawna stanowi ważny obszar badań empirycznych oraz istotny aspekt zarządzania pracownikami sprzedaży (Shaw, Delery, Jenkins i Gupta, 1998). Dotychczasowe studia nad fluktuacją w działach sprzedaży były skoncentrowane głównie na przypadkach dobrowolnych odejść sprzedawców z organizacji. Natomiast wymuszona fluktuacja personelu sprzedażowego stosunkowo rzadko była przedmiotem badań empirycznych, bądź refleksji teoretycznej (Boles, Dudley, Onyemah, Rouzies i Weeks, 2012; Holtom, Mitchell, Lee i Eberly, 2008).

W niniejszym tekście autor zamierza kolejno, opierając się na przeprowadzonych studiach literaturowych: (1) dokonać charakterystyki różnorodnych przypadków wymuszonych odejść sprzedawców z organizacji, (2) omówić tzw. predyktory wymuszonej fluktuacji, (3) ocenić jej konsekwencje oraz (4) sformułować rekomendacje dla menedżerów zespołów sprzedażowych prowadzące do redukcji skali wymuszonych odejść podległych pracowników.

W bogatej literaturze przedmiotu często brakuje wyraźnego rozróżnienia między dobrowolną i wymuszoną postacią fluktuacji. Tymczasem są to diametralnie różne zjawiska.

O ile dobrowolne odejścia sprzedawców z organizacji są zasadniczo wynikiem ich własnych decyzje, o tyle wymuszona fluktuacja obejmuje zwykle przypadki zakończenia współpracy na podstawie decyzji jej kierownictwa.

Odmienne są również przyczyny i konsekwencje obu typów fluktuacji. Sprzedawcy zwykle opuszczają dobrowolnie organizację, szukając lepszych warunków zatrudnienia i pracy poza jej strukturami. Dobrowolne odejścia sprzedawców z organizacji następują również ze względu na trudne do realizacji zadania sprzedażowe. Dla organizacji dobrowolna fluktuacja sprzedawców jest szczególnie dotkliwa wówczas, gdy odchodzą z niej najlepsi bądź nowo zatrudnieni pracownicy sprzedaży (Addima, 2006; Trevor, 2001).

W pierwszej kolejności warto zaznaczyć, że przypadki wymuszonej fluktuacji sprzedawców występują z daleko mniejszą częstotliwością niż ich dobrowolne odejścia $\mathrm{z}$ organizacji. I o ile w warunkach korzystnej koniunktury wyraźnie dominuje dobro- wolna fluktuacja sprzedawców, a fluktuacja wymuszona stanowi wówczas nie więcej niż 10 do $15 \%$ wszystkich przypadków odejść z organizacji, o tyle sytuacja zmienia się diametralnie w okresach spowolnienia gospodarczego. Wówczas wyraźnie spada całkowity poziom fluktuacji w działach sprzedaży, ale większość odejść z organizacji stanowią przypadki fluktuacji wymuszonej (Cybulski, 2013).

Dochodzi do nich głównie za sprawą nacisków, jakie są wywierane na sprzedawców, którzy systematycznie nie wykonują targetów bądź osiaggają słabe lub niezadowalające wyniki. Fluktuacja wymuszona pozostaje w zasadzie pod kontrolą organizacji. Na ogół też prowadzi do poprawy jej sytuacji dzięki obniżce kosztów sprzedaży oraz wzrostowi produktywności zatrudnionego personelu sprzedażowego. Jej uwarunkowania są też zwykle odmienne niż determinanty dobrowolnych odejść pracowników sprzedaży. Zarazem nie absorbuje ona w takim stopniu uwagi praktyków zarządzania jak daleko bardziej powszechna oraz uciążliwa fluktuacja dobrowolna (Stumpf i Dawley, 1981).

\section{Przypadki wymuszonej fluktuacji pracowników sprzedaży}

Najczęściej mało efektywni sprzedawcy sa zwalniani z pracy bądź skłaniani do odejścia z organizacji ze względu na słabe wyniki sprzedażowe. Kwestia ta nie jest w praktyce jednoznaczna, ponieważ termin „słabe wyniki sprzedażowe” może oznaczać zarówno ogólnie niski poziom przychodów osiąganych przez sprzedawcę, jak i niezadowalający poziom realizacji zadań sprzedażowych niezależnie od tego, w jaki sposób zadania te są formułowane. Są to odmienne, chociaż często powiązane ze sobą kategorie.

I tak, jeżeli zadania sprzedażowe są wyznaczane sprzedawcom w oparciu o profesjonalnie przygotowane prognozy sprzedaży i mają realny związek z potencjałem obsługiwanego przez nich obszaru handlowego, to zdecydowana większość pracowników sprzedaży nie ma większych problemów z ich realizacją. Wówczas też fluktuacja w zespołach sprzedażowych kształtuje się na ogół na relatywnie niskim poziomie (Adidam, 2006).

Kolejną kategorią wymuszonej fluktuacji są zwolnienia pracowników sprzedaży 
na skutek splotu niekorzystnych wydarzeń zewnętrznych, wywołanych zwykle przez pogarszającą się koniunkturę rynkową przedsiębiorstwa, aby przetrwać zmuszone sa do znaczacego obniżania kosztów operacyjnych. W okresach złej koniunktury w pierwszej kolejności organizacja pozbywa się gorszych sprzedawców, a więc takich, którzy systematycznie osiagają słabe wyniki sprzedażowe bądź mają problemy z realizacją wyznaczonych zadań (Wells i Muchinsky, 1985).

Wówczas dosyć popularnym sposobem redukowania kosztów, zwłaszcza w okresie przedłużającej się recesji, wydaje się tzw. downsizing działu sprzedaży, który polega przede wszystkim na znaczącej redukcji wielkości zespołów sprzedażowych organizacji oraz na ogół jest powiązany z istotnym obniżeniem wynagrodzeń i stawek prowizyjnych dla sprzedawców (Zoltners, 2009).

Jest to metoda dosyć skuteczna, zwłaszcza w krótkim horyzoncie czasowym, ale niepozbawiona sporego ryzyka, gdyż organizacje w warunkach złej koniunktury często pozbywają się nie tylko słabych, ale też najbardziej kosztownych sprzedawców, a więc takich, którzy osiagają całkiem niezłe wyniki sprzedażowe. Może to prowadzić do wyraźnego zmniejszenia, a nawet załamania się przychodów przedsiębiorstwa, czy wręcz do swoistej implozji organizacji. Działania tego rodzaju zdecydowanie utrudniają późniejszą rewitalizację przychodów oraz poprawę pozycji przedsiębiorstwa w dłuższym horyzoncie czasowym, wówczas gdy sytuacja na rynku wyraźnie się poprawi (Rocki-Lee i DeWitt, 1993).

Wymuszona fluktuacje sprzedawców można więc rozpatrywać także w kontekście zmian zachodzących na rynku w poszczególnych fazach cyklu koniunkturalnego. Chcąc przetrwać okresy osłabionej aktywności gospodarczej, organizacja powinna dostosować się do zmiennych warunków koniunktury gospodarczej. W pierwszej kolejności oznacza to istotną zmianę strategii sprzedażowych oraz systemów motywowania sprzedawców. Często też wymuszona konieczność dokonania radykalnej redukcji wielkości zespołów sprzedażowych.

Pracownicy sprzedaży mogą być też zwolnieni z organizacji również ze względu na złe relacje $z$ klientami bądź bezpośrednim menedżerem, oraz z wyniku konfliktów jakie nieuchronnie powstają w zespołach sprzedażowych. Pozbycie się z organizacji konfliktowych pracowników ma w założeniu prowadzić do poprawy atmosfery w zespołach sprzedażowych i przyczynić sie do ich większej stabilności oraz produktywności (Darmon, 2008).

Wymuszona fluktuacja obejmuje również takie przypadki jak przejście sprzedawców na emeryturę bądź rentę. Zwykle nie mają one żadnego związku z oceną ich pracy. Są to przypadki fluktuacji kontrolowanej dającej się z dużym stopniu przewidzieć. Stanowią one też niewielką część wszystkich odejść sprzedawców z organizacji. Przechodzący na rentę bądź emeryturę sprzedawcy najlepszy okres kariery zawodowej mają zwykle już za sobą. Jednak w wielu przypadkach wraz $\mathrm{z}$ ich odejściem $z$ organizacji dochodzi do utraty przez organizację posiadanej przez nich wiedzy i kontaktów biznesowych (Ramlall, 2003).

Fluktuacja wymuszona ma również miejsce wówczas, kiedy najlepsi sprzedawcy awansują w organizacji, przechodzą na stanowiska menedżerskie w dziale sprzedaży lub w jej innych komórkach. Jak dowodzi obserwacja praktyki zarządzania, promowanie najlepszych sprzedawców na stanowiska menedżerskie w ramach tej samej organizacji może mieć pozytywny wpływ na ich motywację. Jest też skutecznym sposobem przeciwdziałania odpływowi utalentowanych pracowników sprzedaży do konkurencji. Niekiedy jednak jej skutkiem są zakłócenia organizacyjne, które pojawiają się wtedy, gdy awansowani na menedżerów sprzedawcy nie spełnią pokładanych w nich oczekiwań. Awansowanie sprzedawców na stanowiska menedżerskie jest zwykle odwrotnie skorelowane $\mathrm{z}$ ich wiekiem oraz stażem $\mathrm{w}$ organizacji. Promocja sprzedawców na stanowisko menedżerskie ma dla nich oraz dla organizacji największe znaczenie w pierwszym okresie ich kariery zawodowej (Flaherty i Pappas, 2002; Ingram, Keun i Lee, 1990; Cron, Dubinsky i Michaels, 1988).

Inną ważną kategorią fluktuacji wymuszonej są przypadki zwolnień sprzedawców z organizacji na skutek fuzji, badź jej połaczenia się z inną organizacją. Wówczas niemal zawsze ma miejsce redukcja wielkości działu sprzedaży, ponieważ w powstałej na skutek fuzji organizacji zapotrzebowanie na usługi sprzedawców jest na ogół wyraźnie mniejsze.

Niekiedy fuzja lub połączenie się organizacji powoduje radykalną zmianę istniejących modeli biznesowych lub strategii 
sprzedaży. Wówczas co prawda sprzedawcy są potrzebni w tej samej liczbie, ale posiadający zupełnie inne doświadczenie oraz kompetencje zawodowe niż pracownicy działów sprzedaży łączących się organizacji (Batt i Colvin, 2011).

$\mathrm{Na}$ koniec warto wskazać jeszcze jedną zwykle zapoznaną kategorię wymuszonych odejść sprzedawców z organizacji. Dotyczy ona wymuszonej fluktuacji pracowników sprzedaży, którzy nie tylko systematycznie osiaggają dobre, a nawet bardzo dobre wyniki, ale ponadto cieszą się autorytetem oraz sympatią w swoich zespołach sprzedażowych. Częstokroć są oni postrzegani przez swoich bezpośrednich menedżerów jako potencjalne zagrożenia dla ich pozycji w zespole sprzedażowym. Wymuszając ich odejście menedżer pozbywa się w ten sposób przede wszystkim potencjalnych konkurentów ale często również osoby, które podważają w ten czy inny sposób jego władzę bądź autorytet (Founier, Tanner, Chonko i Manolis, 2010).

\section{Predyktory wymuszonej fluktuacji}

Przewidywanie skali zarówno dobrowolnych, jak i wymuszonych odejść sprzedawców z organizacji od dawna nastręcza sporo problemów praktycznych. Szereg zjawisk, jak dowodzi tego praktyka zarządzania oraz wyniki badań empiryczne, może być lepiej lub gorzej wykorzystane do przewidywania skali przyszłej fluktuacji sprzedawców.

I tak, nastawienie sprzedawców do pracy oraz ogólnie ich zadowolenie z organizacji mają, jak się wydaje, znaczący wpływ na skalę ich dobrowolnych odejść $\mathrm{z}$ organizacji. Jednakże warto zauważyć, że wartość zadowolenia sprzedawców z organizacji jako predyktora ich fluktuacji wydaje się niekiedy mocno przeceniana, albowiem istnieje wiele powodów aby, sadzić, że zadowolenie sprzedawców jest słabo powiązane z uzyskiwanymi przez sprzedawców wynikami. Dla organizacji zaś przede wszystkim ważne są wyniki osiagane przez pracowników sprzedaży, a nie ich zadowolenie. Stąd bodaj najważniejszym, choć niepozbawionym również wad predyktorem dobrowolnej fluktuacji sprzedawców, jest ich intencja dobrowolnego odejścia z organizacji (Chandon, Morwitz i Reinartz, 2005).

Natomiast osiagane wyniki oraz absencja sprzedawców w pracy są zwykle dobrym prognostykiem ich potencjalnej wymuszo- nej fluktuacji z organizacji. Generalnie rzecz ujmując, powszechnie znany jest fakt, że sprzedawcy systematycznie osiągający dobre wyniki zwykle nie wykazują wysokiej skłonności do odejścia z organizacji, a jednocześnie organizacje niechętnie pozbywają się dobrze motywowanych oraz produktywnych sprzedawców (Keller, 1984; Stumpf i Dawley, 1981).

\section{Konsekwencje wymuszonych odejść sprzedawców z organizacji}

Fluktuacja sprzedawców zwykle jest postrzegana jako zjawisko wysoce negatywne, mogące na długo zdewastować dział sprzedaży przedsiębiorstwa. Nie zawsze jednak nawet wysoka fluktuacja pracowników sprzedaży wywiera wyłącznie destrukcyjny wpływ na organizację, jej pozycję rynkową oraz sytuację finansową (Adidam, 2006).

Przede wszystkim warto zauważyć, że w oczywistym interesie organizacji jest odejście z niej najmniej efektywnych sprzedawców. Konsekwencje ich wymuszonej fluktuacji są więc pozytywne i prowadzą zwykle do szybkiej poprawy wyników, korzystnie też wpływają na relacje z klientami przedsiębiorstwa. Dodatkowo, kiedy w ramach wymuszonej fluktuacji organizacja uwalnia się od konfliktowych sprzedawców, zakłócających jej funkcjonowanie, to zwykle prowadzi to do poprawy atmosfery w zespołach sprzedażowych, zwiększając ich stabilność oraz produktywność, szczególnie w dłuższej perspektywie czasowej.

Fluktuacja wymuszona zdaje się wyjątkowo korzystna zwłaszcza dla organizacji, którym udaje się „podmienić” mało skutecznych sprzedawców o niskiej motywacji, na wysoce wydajnych i dobrze motywowanych pracowników sprzedaży (Darmon, 2008; Darmon, 2006).

Ma więc ona w założeniu prowadzić do poprawy wyników organizacji oraz wzmocnienia jej pozycji konkurencyjnej. Można ją zatem traktować jako funkcjonalną, czyli pożądaną, podczas gdy fluktuacja dobrowolna zazwyczaj jest dysfunkcjonalna, a więc niepożądana ze względu na jej generalnie negatywne skutki dla organizacji (Hollenbeck i Williams, 1986).

W praktyce jednak również fluktuacja wymuszona często generuje nieprzewidziane uprzednio wyraźnie negatywne skutki dla organizacji zwłaszcza w dłuższym okresie czasu. Przede wszystkim w jej 
wyniku może nastąpić spadek wzajemnego zaufania pomiędzy menedżerami a sprzedawcami, którzy pozostali w organizacji. Szok wywołany przez niezrozumiałe decyzje, błędy w komunikacji z pracownikami sprzedaży w połączeniu $\mathrm{z}$ agresywnym bądź aroganckim zachowaniem menedżerów prowadzi do pogorszenia się relacji w zespołach sprzedażowych. Spada poczucie ich bezpieczeństwa, a często niezamierzonym skutkiem redukcji personelu sprzedażowego może być wysoka dobrowolna fluktuacja w grupie sprzedawców, którzy nie zostali zwolnieni z organizacji wyniku redukcji personelu. Często też konsekwencją wymuszonej fluktuacji jest czasowe zmniejszenie się produktywności pozostających $\mathrm{w}$ organizacji pracowników sprzedaży.

$\mathrm{Na}$ przykład typowa firma przeprowadzająca „odchudzanie” swojej organizacji sprzedażowej musi liczyć się z ponad $30 \%$ wzrostem fluktuacji wśród najlepszych pozostających w jej strukturach sprzedawców. W przypadku zaś przedsiębiorstw, w których poziom odczuwanej przez sprzedawców sprawiedliwości organizacyjnej jest niski i występuje słaby stopień ich „zakorzenienia" wskaźnik ten może być znacząco wyższy i wynosić nawet $112 \%$ (Trevor i Nyberg, 2008; Spreitzer i Mishra, 2002).

Redukcja liczebności personelu sprzedażowego, prowadząc do nieuniknionych turbulencji, powoduje ponadto okresowe naruszenie dobrych relacji organizacji z klientami, którzy byli obsługiwani dotychczas przez sprzedawców zmuszonych do jej opuszczenia (Zoltners, Sinha i Lorimer, 2004, s. 284-285).

Mając więc na uwadze powyższe fakty, należałoby zalecać daleko posuniętą ostrożność przy wdrażaniu wszelkich strategii restrukturyzacyjnych opartych wyłącznie na radykalnej redukcji liczebności zespołów sprzedażowych. I chociaż wydają się one być atrakcyjne ze względu na możliwość szybkiej oraz znaczącej redukcji kosztów operacyjnych, to zarazem uboczne negatywne skutki mogą poważnie ograniczyć spodziewane korzyści (Kacmar i in., 2006; Shaw i in., 2005; Glebbek i Bax, 2004).

Zwłaszcza skumulowane w krótkim przedziale czasowym odejście nazbyt wielu dobrych sprzedawców może całkowicie sparaliżować działalność organizacji, prowadząc do znaczącego pomniejszenia jej przychodów, spadku rentowności, a przede wszystkim utraty ważnych klientów bądź dystrybutorów (Cravens, Meunier-Fitzhugh i Piercy, 2011, s. 305).

\section{Rekomendacje dla menedżerów sprzedaży}

Chociaż szereg składowych wymuszonej fluktuacji sprzedawców znajduje się poza kontrolą przedsiębiorstwa, to może ono w znaczącym stopniu ograniczyć jej skalę. Trudna jest tutaj do przecenienia rola menedżerów sprzedaży.

Przede wszystkim pierwszorzędne znaczenie ma, jak się wydaje, umiejętność pozyskiwania przez menedżerów do organizacji pracowników posiadających wrodzoną chęć i talent do sprzedawania. Te cechy w największym stopniu przesądzają o tym, czy sprzedawcy będą osiągali zadowalające, czy ledwie przeciętne wyniki. Ma to rzecz jasna decydujący wpływ na ich późniejszą ocenę i perspektywy dalszej pracy na rzecz organizacji (Cron, Marshall, Singh, Spiro i Sujan, 2005).

Poza kluczową kwestią pozyskiwania do organizacji sprzedawców o pożądanym profilu osobowościowo-kompetencyjnym wydatny wpływ na ograniczenie skali ich wymuszonych odejść ma sposób wyznaczania i komunikowania przez menedżerów zadań sprzedażowych oraz udzielane im wsparcie w wysiłku sprzedażowym.

Wyznaczenie ,jednoznacznych zadań sprzedażowych" ma ogromny wpływ na motywację, osiągane przez sprzedawców wyniki oraz ich zadowolenie z pracy, a więc pośrednio również na ich ocenę przez organizację i poziom wymuszonej fluktuacji. „Jednoznaczność zadań sprzedażowych” oznacza istnienie łatwo dostrzegalnej zależności pomiędzy działaniami sprzedawców a uzyskanymi wynikami. Jest ona odpowiednio funkcją: (1) wpływu jednostki na osiągany poziom sprzedaży (im wyższy wpływ, tym wieksza jednoznaczność), (2) szybkości, z jaką jednostka uzyskuje informacje o wynikach lub ocenie skuteczności działania (im większa szybkość tym większa jednoznaczność) oraz, (3) dokładności oceny skuteczności działania (im dokładniejsza ocena, tym większa jednoznaczność) (Shapiro i Doyle, 1983).

Natomiast wyznaczenie sprzedawcom nierealistycznych tzn. nazbyt ,wyśrubowanych" oraz niejasnych zadań, co jest niestety dosyć powszechną praktyką, ma 
dewastujący wpływ zarówno na ich morale, jak i skuteczność i w konsekwencji staje się ważną przyczyną wzrostu ich tak dobrowolnej, jak wymuszonej fluktuacji (Adidam, 2006).

Menedżerowie mogą wspierać wysiłek sprzedawców na wiele sposobów. Wsparcie udzielane bezpośrednio sprzedawcom przez ich menedżerów może przybierać różnorodne formy i ma niepodważalny wpływ na skuteczność operacyjną pracowników sprzedaży oraz osiągane wyniki. I tak na przykład menedżerowie poprzez coaching umożliwiają sprzedawcom stałe doskonalenie umiejętności sprzedażowych co korzystnie wpływa na utrzymanie ich wysokiej motywacji.

Następnie dzięki wyższym kwalifikacjom oraz nowym umiejętnościom zawodowym, pozyskanym w wyniku efektywnego przeprowadzonego coachingu sprzedawcy potrafią lepiej budować oraz utrzymywać relacje z klientami. Prowadzi to do zwiększenia ich efektywności i przekłada się na poprawę pozycji w organizacji. W istotnym też stopniu redukuje zagrożenie w postaci utraty pracy i wymuszonego odejścia z organizacji (Bray, 2007; Brum, 2007, Rich, 1997).

\section{Wnioski}

1. Wymuszona fluktuacja sprzedawców jest zjawiskiem wysoce niejednorodnym.

2. Zwykle jej skala jest niewielka, ale w okresie turbulencji jej rozmiary znacząco rosną.

3. Znajdując się pod kontrolą organizacji, jest na ogół zjawiskiem dla niej korzystnym.

4. Pewne przypadki wymuszonej fluktuacji sprzedawców niosą ze sobą jednak negatywne skutki, zwłaszcza w dłuższej perspektywie czasowej.

5. Sa one zwykle bezpośrednia konsekwencją złego zarządzania zespołami sprzedawców i wynikają z braku doświadczenia oraz kompetencji ich menedżerów.

6. Zmiana procedur pozyskiwania sprzedawców do organizacji, wyznaczanie realistycznych i klarownych zadań sprzedażowych $\mathrm{w}$ połączeniu $\mathrm{Z}$ radykalną przebudową systemów wynagradzania sprzedawców pozwalają radykalnie zredukować skale wymuszonych odejść z organizacji i ograniczyć ich najbardziej dotkliwe skutki.

7. Rola menedżerów udzielających, w różnych formach, wsparcia sprzedawcom jest generalnie niedoceniana we wspó1czesnych organizacjach.

\section{Bibliografia}

Abelson, M. i Baysinger, B. (1984). Optimal and Dysfunctional Turnover: Toward an Organizational Level Model. Academy of Management Review, 9(2).

Adidam, Ph.T. (2006). Causes \& Consequences of High Turnover by Sales Professionals. Journal of American Academy of Business, Sep.

Barrick, M.R., Mount, M.K., Strauss i Perkins, J. (1994). Antecedents of involuntary turnover due to reduction in force. Personnel Psychology, Aut, 47, 3. Batt, R. i Colvin, A.J.S. (2011). An Employment Systems Approach to Turnover: Human Resources Practices, Quits, Dissmissals, and Performance. Academy of Management Journal, 54(4), 695-717. Boles, J.S., Dudley, G.W., Onyemah, V., Rouzies, D. i Weeks, A. (2012). Sales Force Turnover and Retention: A Research Agenda. Journal of Personal Selling and Sales Management, XXXII(1). Bray, L. (2007). Reduce Turnover with Effective Recruiting, Retention, and Training. February. Pozyskano z: www.american.payroll.org.

Brum, Sc. (2007). What impact does training have on employee commitment and employee turnover?, Schmidt Labor Research Center Seminar Series.

Budros, A.(2002). The Mean and Lean Firm and Downsizing: Causes of Involuntary and Voluntary Downsizing Strategies. Sociological Forum, 17(2).

Chandon, P., Morwitz, V.G. i Reinartz, W. (2005). Do Intentions Really Predict Behavior? Self-Generated Validity Effects in Survey Research. Journal of Marketing, April 9.

Cravens, D.W., Le Meunier-Fitz Hugh, K. i Piercy, N.F. (2011). The Oxford Handbook of Strategic Sales and Sales Management. Oxford: Oxford University Press.

Cron, W., Marshall, G., Singh, J., Spiro, R. i Sujan, H. (2005). Salesperson selection, training and development: Trends, implications, and research opportunities. Journal of Personal Selling \& Sales Management, $X X V(2), 123-136$.

Cron, W.L., Dubinsky, A.J., Michaels, R.E. (1988). The Influence of Career Stages on Components of Salesperson Motivation. Journal of Marketing; January, 52(1), 78.

Cybulski, K. (2013). Fluktuacja sprzedawców w świetle badań empirycznych. Warszawa: Wydawnictwo Wydziału Zarządzania Uniwersytetu Warszawskiego. Cybulski, K. (2010). Zarządzanie działem sprzedaży firmy. Warszawa: Wydawnictwo Naukowe PWN.

Darmon, R.Y. (2008). The Concept of Salesperson Replacement Value: A Sales Force Turnover Management Tool. The Journal of Personal Selling and Sales Management, Summer. 
Darmon, R.Y. (2006). Sales Force Turnover Diagnosis and Management: An Often Overlooked Source of Productivity. ESSEC Business School Marketing Department Working Paper.

Flaherty, K.E. i Pappas, J.M. (2002). The influence of career stage on job attitudes: toward a contingency perspective. Journal of Personal Selling \& Sales Management, June 22.

Founier, Ch., Tanner, J.F., Chonko, L.B. i Manolis, Ch. (2010). The Moderating Role of Ethical Climate on Salesperson Propensity to Leave. The Journal of Personal Selling \& Sales Management, Winter XXX.

Glebbek, A.C. i Bax, E.H. (2004). Is High Employee Turnover Really Harmful?. An Empirical Tes Using Company Records. Academy of Management Journal, 47(2).

Hollenbeck, J.R. i Williams, Ch.R. (1986). Turnover Functionality Versus Turnover Frequency: A Note on Work Attitudes and Organizational Effectiveness. Journal Psychology, 71(4).

Holtom, B.C., Mitchell, T., Lee, Th.W i Eberly, M.B. (2008). Turnover and Retention Research: A Glance at the Past, a Close Review of the Present, and a Venture into the Future. The Academy of Management Annals, 2(1), 231-274.

Ingram, Th.N. i Keun, S. Lee (1990). Sales Force Commitment and Turnover. Industrial Marketing Management, 19.

Kacpar, K.M., Andrews, M.C., Rooy, D.L.V., Steilber, R.C. i Cerrone, S. (2006). Sure everyone can be replaced... but at what cost? Turnover as a predictor of unit-level performance. Academy of Management Journal, 49, 133-144.

Keller, R.T. (1984). The role of performance and absenteeism in prediction of turnover. Academy of Management Journal, 27(1), 176-183.

Leana, C.R. i Ivancevich, J.M. (1987). Involuntary Job Loss: Institutional Interventions and a Research Agenda. Academy of Management Review, 12, 301-312.

Ramlall, S.A. (2003). Managing Employee Retention as a Strategy for Increasing Organizationa Competitiveness, Applied H.R.M. Research, 8(2), 63-72.

Rich, G.A. (1997). The sales manager as a role model: effects on trust, job satisfaction, and performance of salespeople. Journal of the Academy of Marketing Science, 23 (Fall), 319.

Rocki-Lee DeWitt (1993). The structural consequences of downsizing. Organization Science, 4(1), February.
Salesperson Turnover: Is Your Manager Hiring The Wrong People or Did You Hire The Wrong Manager?, Talent Bits and Bits and Bytes A Blog by TalentQ Consulting, 2013.

Sardar, A. i Patton, M.A. (2004). What Makes A Great Salesperson? Links Between Heritage And The Future, Working Paper.

Shapiro, B. i Doyle, S.X. (1983). Make the Sales Task Clear. Harvard Business Review, November.

Shaw, J.D., Delery, J.E., Jenkins, D.G. i Gupta, N. (1998). An Organization-Level Analysis of Voluntary and Involuntary Turnover. Academy of Management Journal, October, 41(5).

Staw, B.M. (1980). The consequences of turnover Journal of Occupational Behavior, 1, 253-273.

Spreitzer, G.M. i Mishra, A.K. (2002). To stay or to go? Voluntary survivor turnover following an organizational downsizing. Journal of Organizational Behavior, 23, 707-729.

Stumpf, S.A. i Dawley, P.K. (1981). Predicting Voluntary Involuntary Turnover Using Absenteeism and Performance Indices. Academy of Management Journal, 24.

Terborg, J.R. i Lee, Th.W. (1984). A Predictive Study of Organizational Turnover Rates. Academy of Management Journal, 27(4).

Trevor, Ch.O. i Nyberg, A.J. (2008). Keeping your headcount when all about are losing their: Downsizing, voluntary turnover rates, and moderating role of HR practices. The Academy of Management Journal, 51(2).

Trevor, Ch. (2001). Interactions Among Actual Ease-Of- Movement Determinants and Job Satisfaction in the Prediction of Voluntary Turnover. The Academy of Management Journal, 44(4).

Wei, Sh. i Cho, Th.S. (2013). Exploring Involuntary Executive Turnover through a Managerial Discretion Framework. The Academy of Management Review, 30(4).

Wells, D.L. i Muchinsky, P.M. (1985). Performance Antecedents of Voluntary and Involuntary Managerial Turnover. Journal of Applied Psychology, 79(2).

Zoltners, A.A., Shastri, A.N. i Deutsch, H. (2009). Should You Downsize Your Sales Force?, ZS Associates.

Zoltners, A.A., Sinha, P. i Lorimer, S.E. (2009). Building A Winning Sales Force. AMACOM American Management Association.

Zoltners, A.A., Sinha, P. i Lorimer, S.E. (2001). Sales Force Design for Strategic Advantage. Palgrave Macmillan. 